\title{
Expectations for partial splenic arterial embolization simultaneous transcatheter arterial chemoembolization for hepatocellular carcinoma
}

\section{Toru Ishikawa}

Department of Gastroenterology and Hepatology, Saiseikai Niigata Daini Hospital, Niigata 950-1104, Japan

\begin{abstract}
Hepatocellular carcinoma (HCC) is frequently complicated by cirrhosis, and it is not unusual for treatment options to be limited as a result of pancytopenia due to hypersplenism. Partial splenic embolization (PSE) has been performed for thrombocytopenia resulting from hypersplenism. However, the safety and efficacy of concurrent transcatheter arterial chemoembolization (TACE) with PSE for HCC remain unclear. Thrombocytopenia has been improved, and treatment continued using concurrent PSE. In addition, the hepatic functional reserve could be maintained even after treatment for HCC. Concurrent TACE and PSE for HCC with thrombocytopenia can be expected to help maintain a hepatic reserve, and it may contribute to improving the prognosis of HCC. Hence, PSE could lead to an asplenic state. The appearance of Howell-Jolly bodies on a peripheral blood smear is reported useful for assessing splenic function. The appearance of Howell-Jolly bodies is associated with an increased risk for post-splenectomy sepsis/overwhelming post-splenectomy infection in patients with reduced splenic function. These bodies are frequently observed in peripheral erythrocytes after PSE, and when they are present, it is appropriate to administer the pneumococcal vaccine to prevent severe infection. The expectations for PSE combined with TACE for the treatment of HCC associated with cirrhosis are reviewed.
\end{abstract}

Key words: Hepatic functional reserve; hepatocellular carcinoma; partial splenic embolization; thrombocytopenia; transcatheter arterial chemoembolization

Address for correspondence:

Dr. Toru Ishikawa, Department of Gastroenterology and Hepatology, Saiseikai Niigata Daini Hospital, 280-7 Teraji, Niigata 950-1104, Japan. E-mail: toruishi@ngt.saiseikai.or.jp

Received: 24-05-2015, Accepted: 18-06-2015

\section{INTRODUCTION}

Patients with cirrhosis develop hypersplenism (splenomegaly) and decreased platelet counts as their liver fibrosis progresses. ${ }^{[1]}$ Within this clinical context, hepatocellular carcinoma (HCC) is frequently associated with cirrhosis. In addition to surgical procedures such as hepatic resection, liver transplantation, ${ }^{[2]}$ transcatheter arterial chemoembolization (TACE), ${ }^{[3]}$

\begin{tabular}{|l|c|}
\hline \multicolumn{2}{|c|}{ Access this article online } \\
\hline \multirow{2}{*}{ Website: } & Quick Response Code \\
http://www.hrjournal.net/ & \\
DOI: & \\
10.4103/2394-5079.161284 & \\
&
\end{tabular}

percutaneous ethanol injection therapy (PEIT), ${ }^{[4]}$ and radiofrequency ablation (RFA) ${ }^{[5]}$ are all reported to be effective in the treatment of HCC. There are various other therapeutic alternatives including systemic chemotherapy, ${ }^{[6]}$ but thrombocytopenia is a major obstacle in the treatment of HCC. In other words, HCC associated with cirrhosis is often characterized by pancytopenia due to hypersplenism, so it is not uncommon for treatment options to be limited.

This is an open access article distributed under the terms of the Creative Commons Attribution-NonCommercial-ShareAlike 3.0 License, which allows others to remix, tweak, and build upon the work non-commercially, as long as the author is credited and the new creations are licensed under the identical terms.

For reprints contact: reprints@medknow.com

How to cite this article: Ishikawa T. Expectations for partial splenic arterial embolization simultaneous transcatheter arterial chemoembolization for hepatocellular carcinoma. Hepatoma Res 2015;1:155-8. 
Historically so far, splenectomy ${ }^{|7|}$ and partial splenic embolization (PSE) ${ }^{[8]}$ have achieved prolonged improvement for thrombocytopenia due to portal hypertension. Sugawara et al.$^{\mid 9]}$ reported that patients with hypersplenism who underwent combined treatment with splenectomy had improved hepatic functional reserve and became eligible for hepatectomy with post-operative 3- and 5-year survival rates among patients with $\mathrm{HCC}$ associated with cirrhosis reaching $72.3 \%$ and $38.9 \%$, respectively. However, whether splenectomy should be performed simultaneously with HCC treatment is controversial. They recommended that simultaneous splenectomy is appropriate for patients whose HCC could be easily resected while simultaneously performing splenectomy and who had a relatively stable general condition including hepatic functional reserve, while patients who did not satisfy these criteria should first undergo splenectomy followed by assessment of the change in hepatic functional reserve and only then be considered for secondary hepatectomy.

Splenectomy is believed to be more effective in increasing platelet counts than PSE. However, overwhelming post-splenectomy infection (OPSI) and portal vein thrombosis (PVT) are major complications of splenectomy. ${ }^{[10,11]}$ OPSI has a high mortality rate and poor prognosis, especially for patients with HCC.

Hence, Maddison ${ }^{[12]}$ first reported splenic embolization as a treatment for hyper-splenectomy, in 1973; but its use was initially limited by severe complications such as splenic abscess and pneumonia with sepsis. Spigos et al., ${ }^{[8]}$ however, described a PSE procedure for a limited infarct area in 1979 , leading to improved safety and enhanced clinical applications. Like splenectomy, PSE is reported to increase platelet counts and improve hepatic functional reserve and portal hypertension. In the present review, the significance and usefulness of PSE in the treatment of TACE for HCC are discussed.

\section{HCC TREATMENT OF PATIENTS WITH THROMBOCYTOPENIA}

HCC is associated with severe complications in patients with cirrhosis or chronic hepatitis who have severe fibrosis. ${ }^{[13]}$

Although the treatment outcome of HCC has improved recently, intra-hepatic recurrence occurs at a high rate of $10-25 \%$ annually despite radical treatment, and in many patients, HCC recurrence leads to fatal consequences. ${ }^{[14]}$ We previously reported that the combination of total hepatic artery infusion of a powdered formulation of arterial cisplatin (IA-Call; DDP-H) with TACE to treat Stage I/II HCC reduced intra-hepatic distant recurrence ${ }^{[15]}$ and improved survival rates in HCC patients with a Japan Integrated Score of $0-1 .^{[16]}$ However, the exacerbation of thrombocytopenia associated with arterial infusion of anticancer drugs in patients with cirrhosis often restricts subsequent treatment options.

Since both PSE and splenectomy are expected to improve the hepatic functional reserve, there are hopes that HCC treatment combined with PSE represents a valuable treatment modality for patients with thrombocytopenia.

We performed TACE combined with PSE and investigated whether these procedures, when performed simultaneously, could prevent thrombocytopenia, whether there were any complications, and whether there was a secondary effect in the form of improved hepatic functional reserve..$^{[17]}$ In the simultaneous PSE group, platelet count $\left(\times 10^{4} / \mu \mathrm{L}\right)$ increased from $6.54 \pm 2.60$ before TACE to $10.23 \pm 3.93$ at 2 weeks after TACE, even though anti-cancer drugs were administered during the TACE procedure. Meanwhile, in the TACE without PSE group, the platelet count $\left(\times 10^{4} / \mu \mathrm{L}\right)$ decreased from $6.89 \pm 3.21$ before TACE to $4.47 \pm 1.55$ at 2 weeks after TACE. In the simultaneous PSE group, the increased platelet count made it possible to perform loco-regional treatments such as PEIT and RFA. Moreover, assessment of hepatic reserve based on the Child-Pugh score showed that the PSE group experienced temporary worsening from $7.04 \pm 1.05$ to $7.21 \pm 0.99$ at 2 weeks after TACE/PSE, but their scores later improved to $7.00 \pm 1.77$ at 2 months and $6.70 \pm 1.16$ at 6 months after TACE/PSE.

\section{PROBLEMS WITH REDUCED SPLENIC FUNCTION AFTER PSE}

The occurrence of post-splenectomy sepsis (PSS) or OPSI after splenectomy or during reduced splenic function is thought to be associated with a fatality rate of more than $70 \%$.

The appearance of Howell-Jolly bodies in peripheral erythrocytes has drawn attention as an indicator of reduced splenic function. Howell-Jolly bodies are erythrocyte inclusions shown by May-Giemsa staining while they do not appear in healthy individuals, they are apparent in certain blood diseases and in functional asplenia following splenectomy. When we examined the incidence of Howell-Jolly bodies in patients who underwent PSE at our department, we found that they were present in as many as 17 of 95 treated patients $(17.89 \%)^{.18]}$

Comparison with the group that was negative for Howell-Jolly bodies did not reveal any significant differences in residual spleen volume or the splenic infarction rate after PSE. 
However, recent advances in automated analyzers have resulted in a decline in microscopic observation, so there is a tendency for Howell-Jolly bodies, which can only be confirmed visually to be overlooked, and to be less emphasized in clinical settings. Nevertheless, the appearance of Howell-Jolly bodies is associated with an increased risk of PSS/OPSI in patients with reduced splenic function, so the fact that these bodies were frequently observed in peripheral erythrocytes after PSE without any relationship to residual spleen volume or the splenic infarction rate emphasizes the need to visually determine the presence or absence of these entities and when they are present to administer pneumococcal vaccine to prevent severe infection.

Moreover, PSE and splenectomy sometimes induced PVT. PVT is a severe, potentially fatal complication. ${ }^{[19]}$ Some predictive factors of PVT are reported for early detection. ${ }^{[20,21]}$ Early detection of PVT and prompt anticoagulation are effective to avoid serious consequences of PVT. ${ }^{[22]}$ It is necessary to perform PSE recognizing to these problems with reduced splenic function after PSE.

\section{CONCLUSION}

Compared to splenectomy, some advantages of PSE are that it is minimally invasive, can preserve splenic function, and only rarely causes OPSI and PVT. However, PSE also has the risk of complications such as fever, abdominal pain, vomiting, and ascites/pleural effusion, as well as serious symptoms including splenic abscess, and peritonitis, so the decision as to whether to perform the procedure should be a carefully considered one. Myelosuppressed patients receiving anticancer drugs or immuno-suppressants are even more susceptible to the risk of infection. HCC is a tumor-bearing condition, so it is believed to be essential to attempt to minimize the patient's susceptibility to infection due to the asplenia or significantly reduced splenic function. There is no clear evidence to suggest whether PSE should be performed simultaneously with HCC treatment or at a different time. The decision will obviously be influenced by various aspects of the treatment strategy including the location and size of the HCC and any additional therapies, and by the condition of the patient's cirrhosis. Still, simultaneous TACE combined with PSE represents a safe and effective approach in patients who cannot undergo concomitant RFA therapy. Furthermore, TACE combined with PSE is capable of maintaining a hepatic functional reserve. This finding suggests that TACE combined with PSE may represent a treatment strategy for HCC associated with portal hypertension and a multidisciplinary treatment modality for HCC associated with cirrhosis characterized by thrombocytopenia.
In the future, a prospective study of a large patient population is needed to determine whether HCC with portal hypertension should be treated with simultaneous splenectomy or simultaneous PSE.

\section{Financial support and sponsorship}

Nil.

\section{Conflict of interest}

There is no conflict of interest.

\section{REFERENCES}

1. Bashour FN, Teran JC, Mullen KD. Prevalence of peripheral blood cytopenias (hypersplenism) in patients with nonalcoholic chronic liver disease. Am J Gastroenterol 2000;95:2936-9.

2. Bruix J, Gores GJ, Mazzaferro V. Hepatocellular carcinoma: clinical frontiers and perspectives. Gut 2014;63:844-55.

3. Kudo M, Matsui O, Izumi N, Kadoya M, Okusaka T, Miyayama S, Yamakado K, Tsuchiya K, Ueshima K, Hiraoka A, Ikeda M, Ogasawara S, Yamashita T, Minami T; Liver Cancer Study Group of Japan. Transarterial chemoembolization failure/refractoriness: JSH-LCSGJ criteria 2014 update. Oncology 2014;87 Suppl 1:22-31.

4. Shiina S, Teratani T, Obi S, Hamamura K, Koike Y, Omata M. Percutaneous ethanol injection therapy for liver tumors. Eur $J$ Ultrasound 2001;13:95-106.

5. Tateishi R, Shiina S, Teratani T, Obi S, Sato S, Koike Y, Fujishima T, Yoshida H, Kawabe T, Omata M. Percutaneous radiofrequency ablation for hepatocellular carcinoma. An analysis of 1000 cases. Cancer 2005;103:1201-9.

6. Peck-Radosavljevic M. Drug therapy for advanced-stage liver cancer. Liver Cancer 2014;3:125-31.

7. Linton RR, Jones CM, Volwiler W. Portal hypertension; the treatment by splenectomy and splenorenal anastomosis with preservation of the kidney. Surg Clin North Am 1947;27:1162-70.

8. Spigos DG, Jonasson O, Mozes M, Capek V. Partial splenic embolization in the treatment of hypersplenism. AJR Am J Roentgenol 1979;132:777-82.

9. Sugawara Y, Yamamoto J, Shimada K, Yamasaki S, Kosuge T, Takayama T, Makuuchi M. Splenectomy in patients with hepatocellular carcinoma and hypersplenism. J Am Coll Surg 2000;190:446-50.

10. Cullingford GL, Watkins DN, Watts AD, Mallon DF. Severe late postsplenectomy infection. Br J Surg 1991;78:716-21.

11. Butler JC, Breiman RF, Campbell JF, Lipman HB, Broome CV, Facklam RR. Pneumococcal polysaccharide vaccine efficacy. An evaluation of current recommendations. JAMA 1993;270:1826-31.

12. Maddison FE. Embolic therapy of hypersplenism. Invest Radiol 1973;8:280-1.

13. Jemal A, Bray F, Center MM, Ferlay J, Ward E, Forman D. Global cancer statistics. CA Cancer J Clin 2011;61:69-90.

14. Ikai I, Arii S, Okazaki M, Okita K, Omata M, Kojiro M, Takayasu K, Nakanuma Y, Makuuchi M, Matsuyama Y, Monden M, Kudo M. Report of the 17th Nationwide Follow-up Survey of Primary Liver Cancer in Japan. Hepatol Res 2007;37:676-91.

15. Ishikawa T, Higuchi K, Kubota T, Seki K, Honma T, Yoshida T, Kamimura T. Prevention of intrahepatic distant recurrence by transcatheter arterial infusion chemotherapy with platinum agents for stage I/II hepatocellular carcinoma. Cancer 2011;117:4018-25.

16. Ishikawa T, Kubota T, Abe S, Watanabe Y, Sugano T, Inoue R, Iwanaga A, Seki K, Honma T, Yoshida T. Hepatic arterial infusion chemotherapy with cisplatin before radical local treatment of early hepatocellular 
carcinoma (JIS score 0/1) improves survival. Ann Oncol 2014;25:1379-84

17. Ishikawa T, Kubota T, Horigome R, Kimura N, Honda H, Iwanaga A, Seki K, Honma T, Yoshida T. Concurrent partial splenic embolization with transcatheter arterial chemoembolization for hepatocellular carcinoma can maintain hepatic functional reserve. Hepatol Res 2014;44:1056-61.

18. Ishikawa T, Kubota T, Horigome R, Kimura N, Honda H, Iwanaga A, Seki K, Honma T, Yoshida T. Prevalence of Howell-Jolly bodies caused by partial splenic embolization for portal hypertension. Intern Med 2013;52:1765-8.

19. Rattner DW, Ellman L, Warshaw AL. Portal vein thrombosis after elective splenectomy. An underappreciated, potentially lethal syndrome.
Arch Surg 1993;128:565-9.

20. He S, He F. Predictive model of portal venous system thrombosis in cirrhotic portal hypertensive patients after splenectomy. Int J Clin Exp Med 2015;8:4236-42

21. Li MX, Zhang XF, Liu ZW, Lv Y. Risk factors and clinical characteristics of portal vein thrombosis after splenectomy in patients with liver cirrhosis. Hepatobiliary Pancreat Dis Int 2013;12:512-9.

22. Cai M, Zhu K, Huang W, Meng X, He K, Zhou B, Guo Y, Chen J, Shan H. Portal vein thrombosis after partial splenic embolization in liver cirrhosis: efficacy of anticoagulation and long-term follow-up. J Vasc Interv Radiol 2013;24:1808-16. 